\title{
Acute intermittent porphyria: A critical diagnosis for favorable outcome
}

\author{
Chhaya Divecha, Milind S. Tullu, Akanksha Gandhi, Chandrahas T. Deshmukh
}

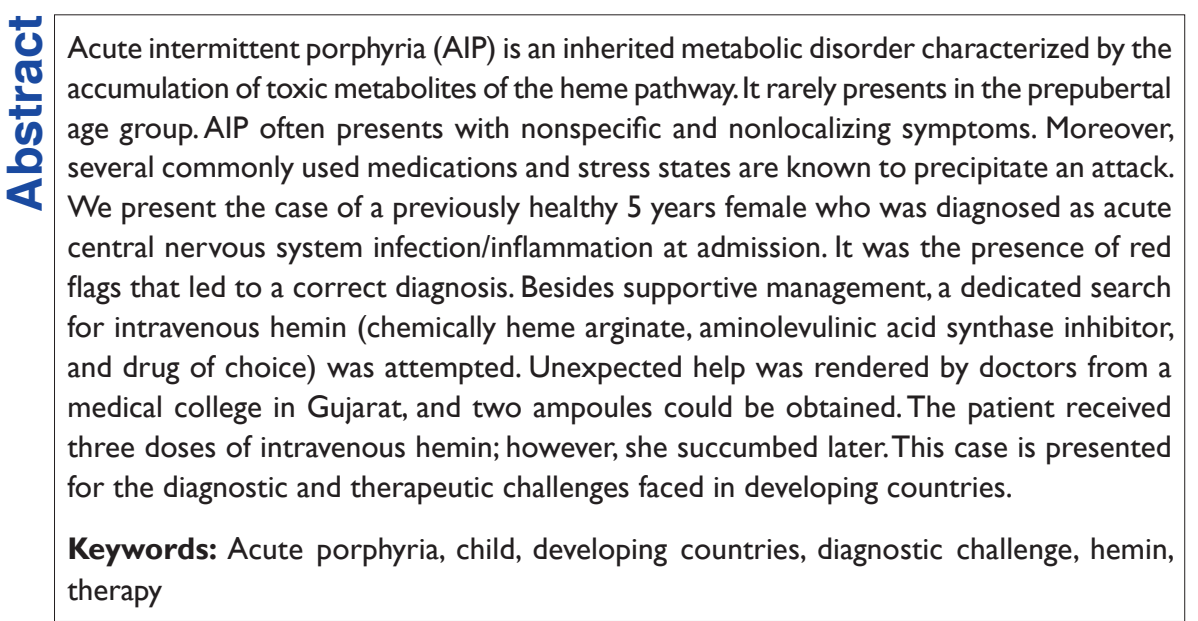

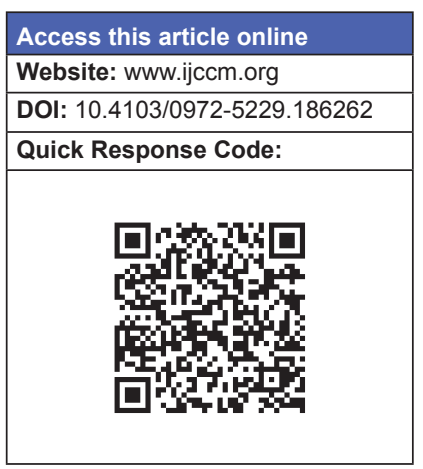

\section{Introduction}

Acute intermittent porphyria (AIP) may present with a paradigm of nonspecific symptoms, often resulting in a mistaken/missed/or delayed diagnosis. AIP is uncommon in children, particularly in prepubertal age. ${ }^{[1,2]}$ Early diagnosis with timely therapy for this life-threatening (yet treatable) condition is essential. We present the diagnostic dilemma and difficulties encountered in the treatment of such a child.

\section{Case Report}

A 5-year-old girl, second of twins, born of a nonconsanguineous marriage presented with complaints of fever since 3 days and complex partial seizures. She had tonic-clonic movements of the left lower limb on the day of admission without evidence of any other neurological findings. There was no history of head

From:

Department of Pediatrics, Pediatric Intensive Care Unit, Seth G.S. Medical

College and KEM Hospital, Mumbai, Maharashtra, India

\section{Correspondence:}

Dr. Milind S. Tullu, "Sankalp Siddhi", Block No. 1, Ground-Floor, Kher Nagar,

Service Road, Bandra (East), Mumbai - 400 051, Maharashtra, India.

E-mail: milindtullu@yahoo.com trauma or tuberculosis. She was developmentally normal and previously healthy. At admission, her heart rate was 100 beats/min, respiratory rate was $28 / \mathrm{min}$, and blood pressure was $100 / 70 \mathrm{mmHg}$. The systemic examination was unremarkable. Investigations (including liver function tests and renal function tests on admission) were normal, except for a total leukocyte count of 14,800/cumm and serum sodium of $113 \mathrm{meq} / \mathrm{L}$. Magnetic resonance imaging brain was suggestive of acute demyelinating encephalomyelitis (ADEM) or meningoencephalitis [Figure 1]. She was treated with injectable methylprednisolone, acyclovir, and phenytoin.

Over the next 4 days, she developed multiple episodes of generalized tonic-clonic convulsions with interictal

This is an open access article distributed under the terms of the Creative Commons Attribution-NonCommercial-ShareAlike 3.0 License, which allows others to remix, tweak, and build upon the work non-commercially, as long as the author is credited and the new creations are licensed under the identical terms.

For reprints contact: reprints@ @medknow.com

How to cite this article: Divecha C, Tullu MS, Gandhi A, Deshmukh CT. Acute intermittent porphyria: A critical diagnosis for favorable outcome. Indian J Crit Care Med 2016;20:428-31. 
drowsiness necessitating valparin and levetiracetam. Subsequently, the seizures were controlled and her sensorium improved over the next 3 days. Owing to hypertension encountered on the $3^{\text {rd }}$ day of steroid therapy, methylprednisolone was discontinued and nifedipine was given to control hypertension. Hyponatremia (119 meq/L) was persistent despite electrolyte correction. On day 17 after admission, she acutely developed flaccid quadriparesis with areflexia and drowsiness with poor respiratory efforts mandating mechanical ventilation in the Pediatric Intensive Care Unit. A computed tomography scan of the brain done thereafter was suggestive of posterior reversible encephalopathy syndrome (PRES) [Figure 2]. Her urine collected in the urine bag was noticed (for the first time) to be dark colored which turned reddish brown on standing [Figure 3]. Workup for hematuria, hemoglobinuria, and myoglobinuria was negative and porphyria was considered. History of skin rash, abdominal pain, or family history of similar complaints was negative. Urinary screening for porphobilinogen (PBG) by the Watson-Schwartz, ultraviolet fluorescence, and the Hoesch's methods was positive. Urinary screening of siblings and parents were negative for porphyria.

Considering the diagnosis of AIP (and after a thorough literature search), harmful drugs such as phenytoin, valparin, and nifedipine were substituted with safer alternatives such as gabapentin and prazosin. High dextrose $(10 \%)$ infusion therapy was initiated and the search for Hemin (intravenous drug of choice) began. Hemin, an orphan drug, is not manufactured in India and has to be procured from Europe or the USA. While its procurement was difficult and tedious due to logistic and financial constraints, we were fortunate to obtain it from doctors in Vadodara (Gujarat) who had undergone a similar sequence of events and had managed to procure it from Europe for their patient. ${ }^{[3]}$ Our patient was given two doses of hemin at $3 \mathrm{~g} / \mathrm{kg}$ for 2 days; however, she succumbed before her dosage schedule could be completed.

\section{Discussion}

Acute porphyrias are disorders of heme synthesis which present with acute attacks, often life-threatening. AIP, an autosomal dominant condition, is the most common acute (hepatic) porphyria. It is characterized by deficient activity of PBG deaminase in the heme biosynthetic pathway. ${ }^{[4,5]}$ The depletion of heme (substrate) and aggregation of intermediate heme metabolites causes neurovisceral manifestations. ${ }^{[4,6]}$

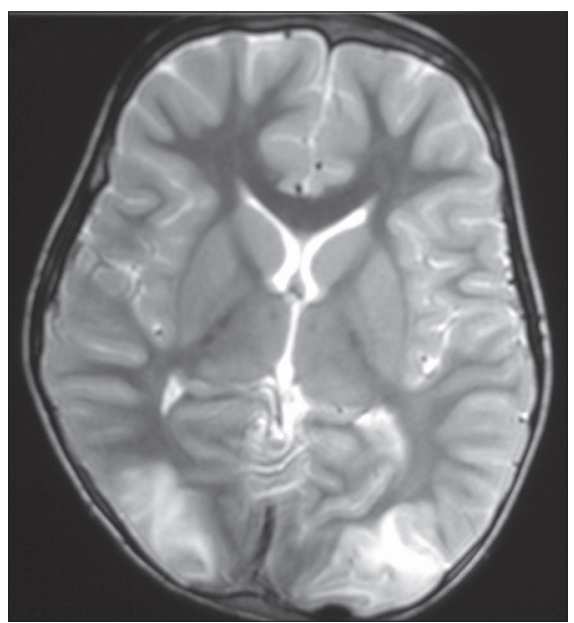

Figure I: Magnetic resonance imaging of brain showing cortical and subcortical T2 hyperintensities along bilateral occipital lobes, parafalcine neuroparenchyma on either side and right frontal lobe suggestive of acute demyelinating encephalomyelitis or meningoencephalitis

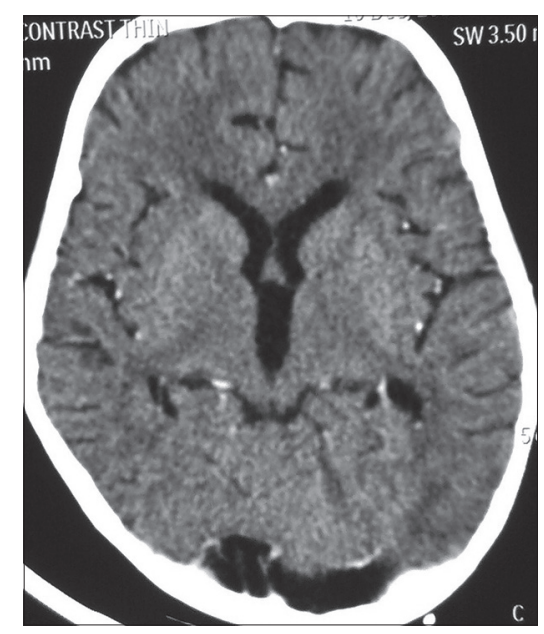

Figure 2: Computed tomography of the brain showing hypodense regions in bilateral occipital lobes white matter extending into high parietal regions and frontal region suggestive of posterior reversible encephalopathy syndrome with dilated ventricular system

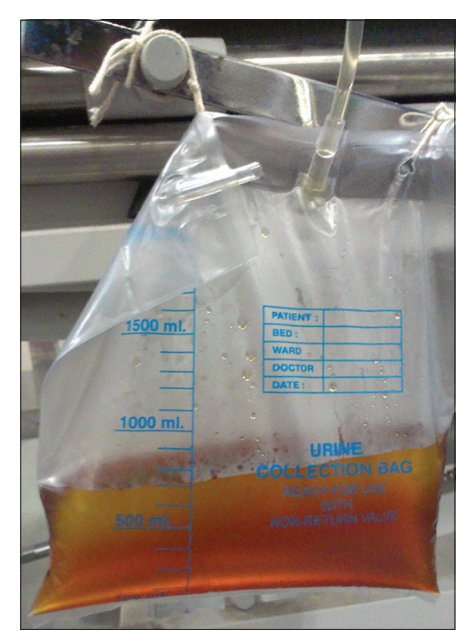

Figure 3: High coloured urine turned reddish brown on standing 
The classic triad of AIP described is of abdominal pain, mental changes, and autonomic dysfunctions. ${ }^{[1,6]}$ However, $90 \%$ of them manifest as autonomic changes (tachycardia and labile hypertension) associated with abdominal pain, constipation, nausea, and vomiting, while $10 \%$ present with central nervous system changes in the form of seizures, impaired consciousness, mental status changes, and encephalopathy. ${ }^{[1,6]}$ Due to its variable penetrance, AIP may remain undiagnosed lifelong. ${ }^{[7]}$ It is often precipitated by environmental and hormonal factors such as drugs, starvation, infection, surgery, stress, menstruation, and steroidal hormones. ${ }^{[2,4,6]}$ However, due to its varied and nonspecific/nonlocalizing manifestations, it is commonly misdiagnosed..$^{[3,5,8,9]}$ In our case, the initial diagnosis of ADEM led us to treat her with steroids and anticonvulsants which were probably detrimental and pushed our patient toward precipitating a crisis. There have been many such reports of AIP being misdiagnosed as epilepsy, PRES, psychosis, Guillain-Barré syndrome, and acute abdomen leading to appendicectomy (and even oophorectomy). ${ }^{[1,5,8-13]}$ Many of the above cases were treated with precipitating drugs, which further aggravated their clinical course. ${ }^{[8,9,11]}$ It was the presence of clues such as dark/reddish urine, new onset hypertension, hyponatremia, proximal weakness (upper limb more involved than lower limb), ${ }^{[14]}$ and temporal association with the recent use of drugs/illness exacerbating the disease that led to a correct diagnosis.

Principles of treatment in AIP generally involve avoidance of porphyrogenic states (triggers of crisis as discussed above) and downregulation of heme synthesis by avoiding fasting and treating the intercurrent illness early. Once an attack is established, treatment modalities available include high carbohydrate diet, use of beta blockers for autonomic manifestations, and substrate reduction by hemin infusion (recommended). ${ }^{[6,7,14]}$ Hemin is an orphan drug manufactured in Europe as heme arginate (Normosang ${ }^{\mathrm{TM}} / \mathrm{CR}$ ) and the United States $\left(\right.$ hematin ${ }^{\mathrm{TM}} /{ }^{\mathrm{CR}}$ ). Its procurement is expensive; it has to be imported, requires special permissions and has a time lag in completing the entire procedure. Although we were fortunate to be extended prompt help by our fraternity, obtaining hemin in India remains a difficult challenge. Other therapies that have been tried are the use of cimetidine and hemodialysis. ${ }^{[15,16]}$ Hemodialysis was contraindicated in our patient due to the presence of deep vein thrombosis.

Thus, acute porphyrias can present as diagnostic dilemmas, unfortunately leading to misdiagnosis/ delayed diagnosis, under treatment and under reporting. Such a patient may present to varying specialties (including the critical care unit) due to a broad spectrum of manifestations, due to which awareness of red flags and a low threshold for screening should be encouraged. Besides acknowledging the benevolent gesture by our medical fraternity in another institution across the country, we wish to highlight the difficulties in obtaining an essentially lifesaving drug due to its orphan status.

\section{Acknowledgment}

The authors thank Dr. A. N. Supe, Dean of Seth G.S. Medical College and K.E.M. Hospital for granting permission to publish this manuscript. The authors also thank Dr. Rupal Dosi (Professor of Medicine, Medical College, Baroda) and her team for their help in managing the case by providing us with the hemin vial.

\section{Contribution of each author}

Dr. Chhaya Divecha and Dr. Milind S. Tullu were involved in conceptualization of the manuscript, collecting patient data, conducting literature search and drafting the manuscript. Both Dr.Chhaya Divecha and Dr. Milind S. Tullu are designated as First Authors of the manuscript. Dr. Akanksha Gandhi and Dr. C.T. Deshmukh supervised the data collection, helped in literature search and revised the manuscript for scientific content. All the authors were involved in clinical management of the patient. Dr. C.T. Deshmukh will act as the guarantor of the paper.

\section{Financial support and sponsorship}

Nil.

\section{Conflicts of interest}

There are no conflicts of interest.

\section{References}

1. Zhao B, Wei Q, Wang Y, Chen Y, Shang H. Posterior reversible encephalopathy syndrome in acute intermittent porphyria. Pediatr Neurol 2014;51:457-60.

2. Dombeck TA, Satonik RC. The porphyrias. Emerg Med Clin North Am 2005;23:885-99, x.

3. Dosi RV, Ambaliya AP, Patell RD, Sonune NN. Challenges in the diagnosis and treatment of a case of acute intermittent porphyria in India. J Postgrad Med 2013;59:241-2.

4. Kauppinen R. Porphyrias. Lancet 2005;365:241-52.

5. Elkhatib R, Idowu M, Brown GS, Jaber YM, Reid MB, Person C. Feigning acute intermittent porphyria. Case Rep Psychiatry 2014;2014:152821.

6. Simon NG, Herkes GK. The neurologic manifestations of the acute porphyrias. J Clin Neurosci 2011;18:1147-53.

7. Ventura P, Cappellini MD, Biolcati G, Guida CC, Rocchi E; Gruppo Italiano Porfiria (GrIP). A challenging diagnosis for potential fatal diseases: Recommendations for diagnosing acute porphyrias. Eur J Intern Med 2014;25:497-505. 
8. Sykes RM. Acute intermittent porphyria, seizures, and antiepileptic drugs: A report on a 3-year-old Nigerian boy. Seizure 2001;10:64-6.

9. Solinas C, Vajda FJ. Neurological complications of porphyria. J Clin Neurosci 2008;15:263-8.

10. Bhat JI, Qureeshi UA, Bhat MA. Acute intermittent porphyria with transient cortical blindness. Indian Pediatr 2010;47:977-8.

11. Kumar B. Acute intermittent porphyria presenting solely with psychosis: A case report and discussion. Psychosomatics 2012;53:494-8.

12. Dimachkie MM, Barohn RJ. Guillain-Barré syndrome and variants. Neurol Clin 2013;31:491-510.
13. Kuo HC, Lee MJ, Chuang WL, Huang CC. Acute intermittent porphyria with peripheral neuropathy: A follow-up study after hematin treatment. J Neurol Sci 2007;260:231-5.

14. Puy H, Gouya L, Deybach JC. Porphyrias. Lancet 2010;375:924-37.

15. Sasaki H. A new approach for the treatment of acute porphyria. Intern Med 1999;38:307-8.

16. Prabahar MR, Manorajan R, Sathiyakumar D, Soundararajan P, Jayakumar M. Hemodialysis: A therapeutic option for severe attacks of acute intermittent porphyria in developing countries. Hemodial Int 2008; $12: 34-8$. 